\title{
Synthesis of tacrine-lophine hybrids
}

\author{
João Paulo B. Lopes, Jessé S. da Costa, Dennis Russowsky, Marco Antonio Ceschi \\ Instituto de Química, Universidade Federal do Rio Grande do Sul, Av. Bento Gonçalves, 9500, Campus do \\ Vale, 91501-970 Porto Alegre - RS, Brazil \\ *mceschi@iq.ufrgs.br
}

Keywords: Synthesis, Tacrine, Lophine

\section{INTRODUCTION}

Our research group has been involved in the development of cholinesterases (ChEs) inhibitors as potential drugs of Alzheimer's disease (AD). ${ }^{1}$ Tacrine (1) was the first approved ChEs inhibitor by the FDA for the treatment of $A D$, although its side effects, the search for tacrine hybrids is very important. The bis(7)-tacrine analogues linked by an alkylene chain (bis $(n)$-cognitin) were prepared and it was proved that these dimeric molecules of tacrine offered a much stronger potency. As part of our studies directed towards the synthesis and biological screening for compounds with ChEs inhibitory activity, we describe herein or studies on the synthesis of a new series of tacrine-lophine hybrids linked by an alkylene chain. ${ }^{2}$
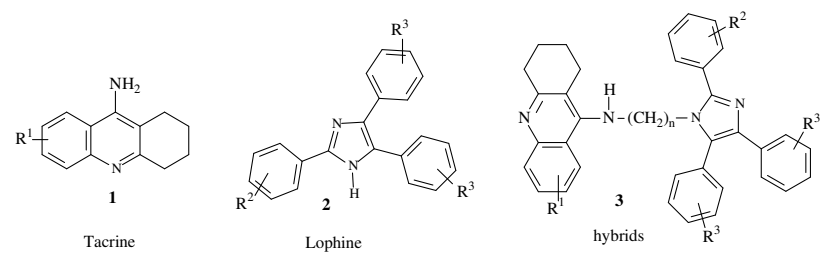

Figure1. Tacrine, Lophine and tacrine-lophine hybrid.

\section{RESULTS AND DISCUSSION}

Tacrine-lophine hybrids linked by an alkylene chain were prepared as described in Scheme 1. Compounds $\mathbf{4}$ were synthesized using a previously reported method. ${ }^{2}$ The one-pot four-component reaction of 4 , aldehydes 5 , benzils 6 and $\mathrm{NH}_{4} \mathrm{OAc}$ (7) was carried out in the presence of several Lewis to produce the respective hybrids $3 \mathbf{a}-\mathbf{g} . \mathrm{InCl}_{3}$ was found as the best catalyst for these reactions. All reactions were performed in refluxing $\mathrm{EtOH}$ for $96 \mathrm{~h}$.

In Table 1 are presented some examples of tacrine-lophine hybrids linked by an alkylene chain. We also synthesized the hybrids bis(7)-lophine and bis(7)-tacrine in order to subject to the ChEs inhibitory activity studies.
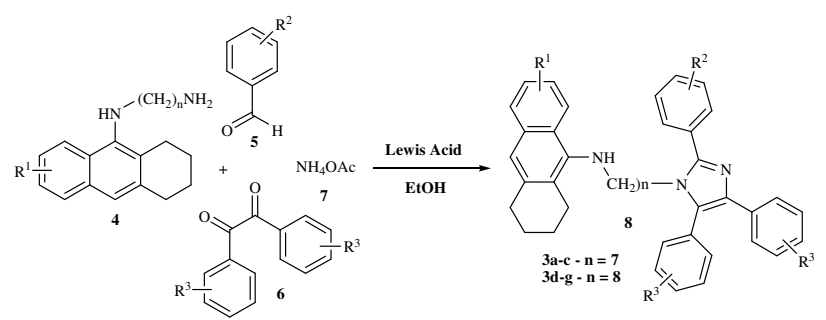

Scheme 1. Synthesis of Tacrine-Lophine hybrids

Table 1. Tacrine-Lophine hybrids.

\begin{tabular}{|c|c|c|c|}
\hline Entry & $\overline{R^{2}}$ & $\left(\mathrm{CH}_{2}\right)_{n}$ & Yield $^{a, b}(\%)$ \\
\hline 1 & $p-\mathrm{Cl}$ & 7 & $3 a-33$ \\
\hline 2 & $p-\mathrm{NO}_{2}$ & 7 & $3 b-54$ \\
\hline 3 & $p$-OMe & 7 & $3 c-54$ \\
\hline 4 & $p-\mathrm{Cl}$ & 8 & $3 d-57$ \\
\hline 5 & $p-\mathrm{NO}_{2}$ & 8 & $3 e-39$ \\
\hline 6 & $p-\mathrm{CN}$ & 8 & $3 f-33$ \\
\hline 7 & $p$-OMe & 8 & $3 g-74$ \\
\hline
\end{tabular}

\section{CONCLUSION}

In summary, we have developed an important four-component one-pot condensation synthesis of tacrine-lophine hybrids. The AChE and BuChE biological screening of several new compounds are currently underway.

\section{ACKNOWLEDGEMENTS}

\section{CNPq, FAPERGS and PROPESQ-UFRGS}

\section{REFERENCES}

${ }^{1}$ Pisoni, D. S., da Costa, J. S.; Gamba, D.; Petzhold, C. L.; Borges, A. C. A.; Ceschi, M. A.; Lunardi, P.; Gonçalves, C. A. S.; Eur. J. Med. Chem. 2010, 45, 526. .

${ }^{2}$ Kozurkova, M.; Hamulakova, S.; Gazova, Z.; Paulikova, H.; Kristian, P ,Pharmaceuticals 2011, 4, 382. 